\title{
Transdermal Estrogen
}

National Cancer Institute

\section{Source}

National Cancer Institute. Transdermal Estrogen. NCI Thesaurus. Code C61440.

A transdermal formulation containing the synthetic form of estradiol, the most potent, endogenously produced estrogen. Upon topical administration, estradiol diffuses through the cell membrane and binds to and activates specific intracellular estrogen receptors located on estrogen-responsive tissues, including the reproductive tract, breast, pituitary, hypothalamus, liver, and bone. The activated ligand-receptor complex binds to estrogen response elements on DNA and promotes the transcription of genes involved in the functioning of the female reproductive system and secondary sex characteristics. In addition, estradiol inhibits the pituitary secretion of the gonadotropins luteinizing hormone (LH) and follicle stimulating hormone (FSH) through a negative feedback mechanism. 